\title{
Variation in airways resistance when defined over different ranges of airflows
}

\author{
P. W. LORD AND J. M. EDWARDS \\ From the MRC Toxicology Unit, Clinical Section, St. Bartholomew's Hospital Medical College, \\ London EC1M 6BQ, UK
}

Lord, P. W., and Edwards, J. M. (1978). Thorax, 33, 401-405. Variation in airways resistance when defined over different ranges of airflows. In eight normal subjects airways resistance (Raw) was assessed over six ranges of airflow (about zero flow at both minimum and maximum lung volumes) using an automated whole body plethysmograph. The intervals of flow used were $21 \mathrm{~s}^{-1}$ and $11 \mathrm{~s}^{-1}$ spanning zero flow, and $11 \mathrm{~s}^{-1}$ and $0.51 \mathrm{~s}^{-1}$ measured up to and from zero flow. The wider intervals gave less variable results, the coefficients of variation being of the order $11 \%, 15 \%$, and $22 \%$ for the 2,1 , and $0.51 \mathrm{~s}^{-1}$ intervals respectively. In all subjects, at minimum volume Raw was some 1.5 times greater when measured over the ranges at end-expiration than at start-expiration; at maximum volume $\mathrm{Raw}$ was some 1.3 times greater when measured over the ranges at end-inspiration than at start-expiration. A slight increase in the slopes of the oscilloscope traces used to determine Raw was observed at minimum volume compared with those at maximum volume.

In view of the substantial differences reported it is essential that the exact range of flow, and the respiratory phase used, is described when reporting measurements of Raw. Least variability is obtained by estimating slopes over a wide interval of flow, such as 1 or $21 \mathrm{~s}^{-1}$.

Non-linearities in the pressure (p)-flow (V) relationship in the airways, and changes in lung volume, give rise to differences in airways resistance (Raw) when it is measured over different ranges of airflow and at different parts of the respiratory cycle. This is so even at the low flow rates employed using the whole body plethysmograph to determine Raw. Without $a$ priori knowledge of individual $\mathrm{p}-\mathrm{V}$ relationships the magnitude of the differences cannot be predicted, and we therefore determined this experimentally in normal subjects.

The determination of Raw (DuBois et al., 1956) usually entails measuring on an oscilloscope the slope of traces of the plethysmograph pressure signal $\left(\mathbf{P}_{\mathrm{P}}\right)$ displayed against the airflow signal $(\mathrm{V})$ over a region near zero flow (Figure). When changes in plethysmograph pressure are related to changes in alveolar pressure these slopes, $S=\Delta P_{p} / \Delta V$, are linearly related to airways resistance. In their original description of the method DuBois et al. (1956) recommended that the range of airflow used to determine the slope should be $11 \mathrm{~s}^{-1}$ inspiration (positive flows) to $11 \mathrm{~s}^{-1} \mathrm{ex}-$ piration (negative flows). Later publications make other recommendations-for example, at $0.51 \mathrm{~s}^{-1}$ inspiration (DuBois, 1964) at 0.5 or $1.01 \mathrm{~s}^{-1}$ (Cotes, 1975), and at 0.5 to $1.011 \mathrm{~s}^{-1}$ inspiration (Bouhuys, 1974). In reports of experiments and surveys that have employed plethysmography the ranges used have varied (Butler et al., 1960; Kerr, 1973; Sackner and Landa, 1973; Stamm et al., 1976), and often the direction of flow is not stated (Lloyd and Wright, 1963; Gayrard et al., 1975; Hruby and Butler, 1975). Even when the direction of flow is given it is generally not clear whether the measurements were obtained at the start or end of the inspiratory or expiratory phases. Sometimes no range at all is given, as for example in Spicer et al. (1962).

Variability in the measurement of Raw over a given range of flow will be due to turbulance in the airflow, to physiological changes in the airways that alter the $\mathrm{p}-\mathrm{V}$ relationship, and to experi- 


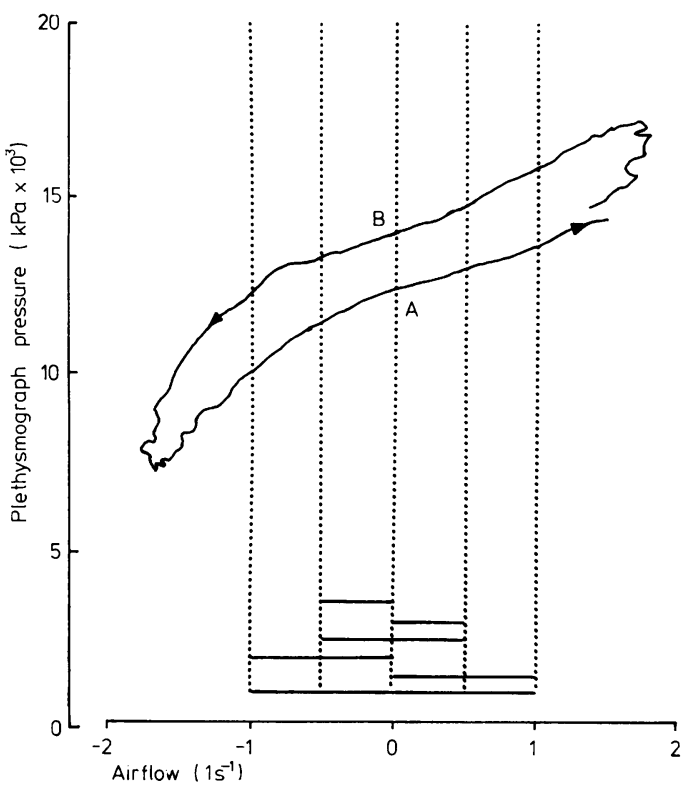

Figure Typical trace of plethysmograph pressure against airflow for one respiratory cycle (case 6). The horizontal bars indicate the six ranges of flow. $A$ is minimum volume point and $B$ maximum volume point. Expiratory flows are negative, inspiratory flows positive. Arrows indicate direction of trace with time.

mental error. Differences in this variability between ranges of measurement have also been determined experimentally.

\section{Materials and methods}

A constant volume whole body plethysmograph (DuBois et al., 1956a, b) was used, of a design similar to that described by Comroe et al. (1959). Measurements of Raw and thoracic gas volume (Vtg) were made using this apparatus following the computer-controlled procedure described by $\stackrel{\vec{P}}{\rightarrow}$ Lord and Brooks (1977). Eight normal, nonsmoker subjects performed six successive shallowpanting manoeuvres to obtain measurements of Raw and Vtg. During each manoeuvre seven com- $\mathbb{Q}$ plete breathing cycles were examined for Raw and for each of these cycles 12 values were ob- a tained from the airflow and plethysmograph. pressure signals by calculating the slopes $S$ over the six ranges of flow -1 to $1,-1$ to 0,0 to 1 , o -0.5 to $0.5,-0.5$ to 0 , and 0 to $0.51 \mathrm{~s}^{-1}$ about the points of zero flow at end-expiration (minimum volume point) and at end-inspiration (maximum volume point) (see Figure). The subjects were instructed to pant near their functional residual $\subseteq$ capacity at a frequency of $2 \mathrm{~Hz}$ (which was indi- 을 cated to them by a metronome).

\section{Results}

All the results presented here are in terms of the slopes, which may be translated into resistance using the formula

$\mathrm{Raw}=2.99 \mathrm{FS} /(\mathrm{Vtg}+\mathrm{D})-0.02, \mathrm{kPa} \mathrm{l}^{-1} \mathrm{~S} \ldots$ (1) where $F$ and $D$ (Table 1 ) are respectively factors for body volume displacement in the plethysmograph and a volume correction for the mouthpiece and subject's dead space; Vtg is the observed $\overrightarrow{\vec{B}}$ thoracic gas volume and the constant $0.02 \mathrm{kPa} \mathrm{l}^{-1} \mathrm{~s}$ is the pneumotachograph resistance. For any particular subject, at a given Vtg, Raw is linearly related to the slope $S$.

The experiment conformed to a factorial design with the six flow ranges nested within reading within subjects. The part of the breathing cycle (maximum and minimum volume) was included as a two-level factor, and the seven loops were treated as replicates. An analysis of variance was carried out (Table 2) to investigate the contributions of the factors to the variation in the slopes. All the factors, including the interaction

Table 1 Details of the subjects and their mean Raw and Vtg

\begin{tabular}{|c|c|c|c|c|c|c|c|c|}
\hline $\begin{array}{l}\text { Case } \\
\text { No. }\end{array}$ & Sex & Age & $F^{*}$ & $D, 1 \dagger$ & $\begin{array}{l}\text { Mean Raw } \\
\mathrm{kPal}^{-1} \mathrm{~s}\end{array}$ & $( \pm S D)$ & $\underset{I}{M e a n ~ V t g \S}$ & $( \pm S D)$ \\
\hline $\begin{array}{l}1 \\
2 \\
3 \\
4 \\
5 \\
6 \\
7 \\
8\end{array}$ & $\begin{array}{l}\mathbf{F} \\
\mathbf{F} \\
\mathbf{M} \\
\mathbf{M} \\
\mathbf{M} \\
\mathbf{F} \\
\mathbf{F} \\
\mathbf{M}\end{array}$ & $\begin{array}{l}24 \\
48 \\
31 \\
51 \\
29 \\
23 \\
20 \\
47\end{array}$ & $\begin{array}{l}0.89 \\
0.89 \\
0.88 \\
0.86 \\
0.89 \\
0.91 \\
0.90 \\
0.89\end{array}$ & $\begin{array}{l}0 \cdot 19 \\
0 \cdot 19 \\
0 \cdot 20 \\
0 \cdot 22 \\
0 \cdot 19 \\
0 \cdot 16 \\
0 \cdot 18 \\
0 \cdot 19\end{array}$ & $\begin{array}{l}0.081 \\
0.128 \\
0.062 \\
0.070 \\
0.084 \\
0.212 \\
0.134 \\
0.067\end{array}$ & $\begin{array}{l}(0.009) \\
(0.010) \\
(0.016) \\
(0.010) \\
(0.010) \\
(0.020) \\
(0.022) \\
(0.008)\end{array}$ & $\begin{array}{l}3 \cdot 51 \\
2 \cdot 04 \\
3 \cdot 79 \\
3 \cdot 41 \\
3 \cdot 81 \\
2 \cdot 90 \\
2 \cdot 49 \\
6 \cdot 82\end{array}$ & $\begin{array}{l}(0.24) \\
(0.21) \\
(0.10) \\
(0.24) \\
(0.10) \\
(0.08) \\
(0.14) \\
(0.14)\end{array}$ \\
\hline
\end{tabular}

*Factor for body value displacement in plethysmograph.

†Dead space, including pneumotachograph dead space.

$\ddagger$ Mean of six readings, measured for flows between 0 to $1.01 \mathrm{~s}^{-1}$ at start of inspiration.

$\S$ Mean of six readings. Measured at end-expiration. 
Table 2 Analysis of variance table for both parts of respiratory cycle combined. All variance ratios are significant, $\mathrm{P}<0.001$

\begin{tabular}{lcll}
\hline Sources of variation & $\begin{array}{l}\text { Degrees of } \\
\text { freedom }\end{array}$ & $\begin{array}{l}\text { Mean sum } \\
\text { of squares }\end{array}$ & $\begin{array}{l}\text { Variance } \\
\text { ratio (over } \\
\text { residual) }\end{array}$ \\
\hline Between subjects & 7 & 1.8990 & 1651 \\
Between readings & 40 & 0.0257 & 22 \\
Part of respiratory cycle & 1 & 0.1606 & 139 \\
Flow range & 5 & 0.0935 & 81 \\
Part of cycle X flow range & 5 & 0.5517 & 479 \\
Residual & 3945 & 0.00115 & \\
Corrected total & 4003 & & \\
Total observations & 4032 & & \\
Missing values & 28 & & \\
\hline
\end{tabular}

between the two parts of the breathing cycle and the flow ranges, were found to contribute highly significantly to variations among the slopes $(P<0.001)$. Repeating the analysis for each part of the breathing cycle separately also showed a highly significant variation $(P<0.001)$ between the ranges, as might be expected.

The means of the slopes for each subject over each range are shown in Table 3 . For all subjects the slope decreased significantly $(P<0.001)$ as the respiratory cycle passed through either of the zero flow points. That is, at minimum volume the slopes over an inspiratory (positive) flow range were less than those over an expiratory (negative range) flow range, by a factor of some 1.5 . At maximum volume the opposite was true, the slopes at end-inspiration being some 1.3 greater than at start-expiration. Thus the best agreement between the two parts of the respiratory cycle was between end-inspiration and start-expiration. On both parts of the cycle the ranges that spanned zero flow gave intermediate values.

The slopes over the six ranges varied widely; in some subjects the largest value was about twice the smallest. Over all subjects the only two means that were not significantly different were those for the ranges 0 to $0.51 \mathrm{~s}^{-1}$ and 0 to $1 \mathrm{~s} \mathrm{~s}^{-1}$ at the start of inspiration.

In general the larger the flow interval the smaller the standard deviation of the slopes measured over it. The -1 to $11 \mathrm{~s}^{-1}$ range slopes were least variable (coefficient of variation $\sim 11 \%$ ). The coefficient of variation of the intervals of $11 \mathrm{~s}^{-1}$ were of the order of $15 \%$ and for $0.51 \mathrm{~s}^{-1}$ the coefficient of variation was about $22 \%$.

Agreement among the subjects on their ranking of the coefficients of variation of Raw over the six airflow ranges, at the minimum and maximum volume points separately, was tested by calculating the coefficient of concordance on the ranks, taking flow ranges as 'competitors' and subjects as 'judges'. This showed in both cases that the sub-

Table 3 Means and standard deviations $(n=42)$ of slopes for each subject over each range of flow: at minimum volume and maximum volume

\begin{tabular}{|c|c|c|c|c|c|c|c|c|c|}
\hline & $\begin{array}{l}\text { Slopes (Sto } \\
\text { Case No. } \\
I\end{array}$ & dard deviat & 3 & 4 & 5 & 6 & 7 & 8 & Mean \\
\hline Range; $l s^{-1}$ & \multicolumn{9}{|c|}{ Minimum volume point } \\
\hline$-1,1$ & $\begin{array}{c}0.189 \\
(0.023)\end{array}$ & $\begin{array}{c}0.166 \\
(0.020)\end{array}$ & $\begin{array}{c}0.137 \\
(0.021)\end{array}$ & $\begin{array}{c}0.147 \\
(0.015)\end{array}$ & $\begin{array}{c}0.186 \\
(0.021)\end{array}$ & $\begin{array}{c}0.323 \\
(0.035)\end{array}$ & $\begin{array}{c}0.189 \\
(0.022)\end{array}$ & $\begin{array}{c}0.273 \\
(0.026)\end{array}$ & $\begin{array}{c}0.201 \\
(0.065)\end{array}$ \\
\hline$-1,0$ & $\begin{array}{c}0.244 \\
(0.039)\end{array}$ & $\begin{array}{c}0.211 \\
(0.036)\end{array}$ & $\begin{array}{c}0.159 \\
(0.034)\end{array}$ & $\begin{array}{c}0.173 \\
(0.024)\end{array}$ & $\begin{array}{c}0.230 \\
(0.035)\end{array}$ & $\begin{array}{c}0.410 \\
(0.062)\end{array}$ & $\begin{array}{c}0.236 \\
(0.035)\end{array}$ & $\begin{array}{c}0.333 \\
(0.041)\end{array}$ & $\begin{array}{c}0.250 \\
(0.088)\end{array}$ \\
\hline 0,1 & $\begin{array}{c}0.136 \\
(0.026)\end{array}$ & $\begin{array}{c}0.122 \\
(0.020)\end{array}$ & $\begin{array}{c}0.119 \\
(0.027)\end{array}$ & $\begin{array}{c}0 \cdot 122 \\
(0 \cdot 021)\end{array}$ & $\begin{array}{c}0.148 \\
(0.028)\end{array}$ & $\begin{array}{c}0.244 \\
(0.026)\end{array}$ & $\begin{array}{c}0.145 \\
(0.027)\end{array}$ & $\begin{array}{c}0.218 \\
(0.024)\end{array}$ & $\begin{array}{c}0.157 \\
(0.051)\end{array}$ \\
\hline$-0.5,0.5$ & $\begin{array}{c}0.165 \\
(0.028)\end{array}$ & $\begin{array}{c}0.141 \\
(0.017)\end{array}$ & $\begin{array}{c}0.124 \\
(0.023)\end{array}$ & $\begin{array}{c}0.139 \\
(0.019)\end{array}$ & $\begin{array}{c}0.166 \\
(0.028)\end{array}$ & $\begin{array}{c}0.280 \\
(0.032)\end{array}$ & $\begin{array}{c}0.167 \\
(0.023)\end{array}$ & $\begin{array}{c}0.242 \\
(0.023)\end{array}$ & $\begin{array}{c}0.178 \\
(0.057)\end{array}$ \\
\hline$-0 \cdot 5,0$ & $\begin{array}{c}0.210 \\
(0.051)\end{array}$ & $\begin{array}{c}0.175 \\
(0.039)\end{array}$ & $\begin{array}{c}0.142 \\
(0.049)\end{array}$ & $\begin{array}{c}0.166 \\
(0.033)\end{array}$ & $\begin{array}{c}0.205 \\
(0.054)\end{array}$ & $\begin{array}{c}0.349 \\
(0.064)\end{array}$ & $\begin{array}{c}0.207 \\
(0.046)\end{array}$ & $\begin{array}{c}0.291 \\
(0.042)\end{array}$ & $\begin{array}{c}0.218 \\
(0.080)\end{array}$ \\
\hline \multirow[t]{2}{*}{$0,0.5$} & $\begin{array}{c}0.138 \\
(0.030)\end{array}$ & $\begin{array}{c}0.125 \\
(0.022)\end{array}$ & $\begin{array}{c}0.117 \\
(0.034)\end{array}$ & $\begin{array}{c}0.128 \\
(0.027)\end{array}$ & $\begin{array}{c}0.146 \\
(0.031)\end{array}$ & $\begin{array}{c}0.244 \\
(0.032)\end{array}$ & $\begin{array}{c}0.144 \\
(0.028)\end{array}$ & $\begin{array}{c}0.214 \\
(0.031)\end{array}$ & $\begin{array}{c}0.157 \\
(0.052)\end{array}$ \\
\hline & \multicolumn{9}{|c|}{ Maximum volume point } \\
\hline & $\begin{array}{l}0.181 \\
0.023)\end{array}$ & $\begin{array}{c}0.158 \\
(0.018)\end{array}$ & $\begin{array}{c}0.185 \\
(0.017)\end{array}$ & $\begin{array}{c}0.150 \\
(0.019)\end{array}$ & $\begin{array}{c}0.195 \\
(0.017)\end{array}$ & $\begin{array}{c}0.324 \\
(0.034)\end{array}$ & $\begin{array}{c}0.178 \\
(0.019)\end{array}$ & $\begin{array}{c}0.317 \\
(0.033)\end{array}$ & $\begin{array}{c}0.211 \\
(0.068)\end{array}$ \\
\hline$-1,0$ & $\begin{array}{c}0.165 \\
(0.034)\end{array}$ & $\begin{array}{c}0.141 \\
(0.023)\end{array}$ & $\begin{array}{c}0.166 \\
(0.022)\end{array}$ & $\begin{array}{c}0.142 \\
(0.025)\end{array}$ & $\begin{array}{c}0.181 \\
(0.025)\end{array}$ & $\begin{array}{c}0.272 \\
(0.031)\end{array}$ & $\begin{array}{c}0.167 \\
(0.021)\end{array}$ & $\begin{array}{c}0.300 \\
(0.064)\end{array}$ & $\begin{array}{c}0.191 \\
(0.065)\end{array}$ \\
\hline 0,1 & $\begin{array}{c}0.205 \\
(0.031)\end{array}$ & $\begin{array}{c}0.181 \\
(0.029)\end{array}$ & $\begin{array}{c}0.209 \\
(0.026)\end{array}$ & $\begin{array}{c}0.167 \\
(0.030)\end{array}$ & $\begin{array}{c}0.213 \\
(0.033)\end{array}$ & $\begin{array}{c}0.382 \\
(0.053)\end{array}$ & $\begin{array}{c}0.194 \\
(0.038)\end{array}$ & $\begin{array}{c}0.345 \\
(0.029)\end{array}$ & $\begin{array}{c}0.237 \\
(0.082)\end{array}$ \\
\hline$-0.5,0.5$ & $\begin{array}{c}0.166 \\
(0.024)\end{array}$ & $\begin{array}{c}0.160 \\
(0.028)\end{array}$ & $\begin{array}{c}0.180 \\
(0.028)\end{array}$ & $\begin{array}{c}0.144 \\
(0.024)\end{array}$ & $\begin{array}{c}0.184 \\
(0.025)\end{array}$ & $\begin{array}{c}0.305 \\
(0.042)\end{array}$ & $\begin{array}{c}0.176 \\
(0.028)\end{array}$ & $\begin{array}{c}0.283 \\
(0.032)\end{array}$ & $\begin{array}{c}0.200 \\
(0.063)\end{array}$ \\
\hline$-0 \cdot 5,0$ & $\begin{array}{c}0 \cdot 150 \\
(0 \cdot 042)\end{array}$ & $\begin{array}{c}0.137 \\
(0.039)\end{array}$ & $\begin{array}{c}0.159 \\
(0.035)\end{array}$ & $\begin{array}{c}0.128 \\
(0.041)\end{array}$ & $\begin{array}{c}0.165 \\
(0.038)\end{array}$ & $\begin{array}{c}0.245 \\
(0.045)\end{array}$ & $\begin{array}{c}0.164 \\
(0.042)\end{array}$ & $\begin{array}{c}0.227 \\
(0.046)\end{array}$ & $\begin{array}{c}0.173 \\
(0.057)\end{array}$ \\
\hline $0,0 \cdot 5$ & $\begin{array}{c}0.187 \\
(0.046)\end{array}$ & $\begin{array}{c}0.182 \\
(0.036)\end{array}$ & $\begin{array}{c}0.195 \\
(0.034)\end{array}$ & $\begin{array}{c}0.164 \\
(0.041)\end{array}$ & $\begin{array}{c}0.202 \\
(0.050)\end{array}$ & $\begin{array}{c}0.350 \\
(0.052)\end{array}$ & $\begin{array}{c}0.194 \\
(0.045)\end{array}$ & $\begin{array}{c}0.337 \\
(0.041)\end{array}$ & $\begin{array}{c}0.226 \\
(0.081)\end{array}$ \\
\hline
\end{tabular}


jects were concordant $(\mathrm{P}<0 \cdot 001)$, Raw being less variable the larger the flow interval. Restricting the tests to the three $1 \mathrm{l} \mathrm{s}^{-1}$ and to the two $0.51 \mathrm{~s}^{-1}$ intervals did not show any agreement among the subjects and hence expiratory ranges were not significantly any more or less variable than inspiratory ranges.

Overall, the slopes at minimum volume were 0.01 higher than at maximum volume $(P<0.001)$. There were no differences in variability between these two parts of the respiratory cycle.

\section{Discussion}

Significant and substantial differences in slopes of the $\mathbf{P}_{p}$ versus $\mathbf{V}$ traces used to estimate Raw have been shown in normal subjects when measurements are made over various ranges of airflow. The only exception was for the two ranges 0 to 0.5 and 0 to $11 \mathrm{~s}^{-1}$ at the start of inspiration. It should be noted that the results over a 0 to $0.51 \mathrm{~s}^{-1}$ range are generally more variable than over the larger range.

The differences in slopes over different ranges would give rise to variation in Raw by virtue of equation (1), and as for the slopes these variations would be substantial. For the purposes of comparison between studies the range of flow over which Raw was measured should be given, as well as the part of the respiratory cycle used. This is not always done at present.

Near maximum volume when the lung is distended a lower resistance would be expected and this we have confirmed when all the ranges are pooled, but as Table 3 shows this was not consistent over each range. We measured Vtg at minimum volume but the experimental technique did not allow us to measure it also at maximum volume when it would be about 0.51 more.

We have shown that the airways resistance is greatest at end-expiration and end-inspiration. The former represents the resistance when the lung volume is at its least and also when the airways are under compressive forces, which would also tend to narrow their calibre. The higher value of resistance at end-inspiration, when the lungs are more inflated and the transpulmonary pressure is tending to increase airway calibre we cannot explain, but it must reflect dynamic changes in the lung as the volume changes and represents an asymmetry between the inspiratory and expiratory phases.

The differences in Raw between different ranges could be used together to give a more complete discription of lung function, and it may be that these differences will prove to be of more clinical and epidemiological value than a single estimation $\overrightarrow{\bar{\rho}}$ of Raw over one range of flow.

We measured slopes over intervals of flow and no attempt has been made to compare these measurements with the values obtained for $\tan -\frac{\widehat{\Phi}}{\Omega}$ gents to the $P_{p}$ against $V$ traces.

Whatever the part of the respiratory cycle used, our results indicate that a larger range is prefer- $-\overrightarrow{0}$ able to a small one in giving less variability, $\vec{\overrightarrow{ }}$ though it must be borne in mind that some sub- $\omega$ jects may have difficulty in achieving flows of $1 \mathrm{l} \mathrm{s}^{-1}$ while performing the panting manoeuvre. $\stackrel{x}{\dot{\omega}}$ Our measurements thus show that small rangese near zero flow give the least reproducible results, $\omega$ even though there is less turbulence at low flow. For routine work we recommend a flow range ofo -0.5 to $0.51 \mathrm{~s}^{-1}$.

\section{References}

Bouhuys, A. (1974). Breathing, Physiology, Environ- $\vec{\varphi}$ ment and Lung Disease, p. 160. Grune and Stratton, New York.

Butler, J., Caro, C. G., Alcala, R., and DuBois, A. B.O (1960). Physiological factors affecting airways resistance in normal subjects and in patients witho obstructive respiratory disease. Journal of Clinicalo Investigation, 39, 584-591.

Comroe, J. H., Botelho, S. Y., and DuBois, A. B. $\stackrel{2}{\vec{P}}$ (1959). Design of a body plethysmograph for study윽 ing cardiopulmonary physiology. Journal of Applied Physiology, 14, 439-444.

Cotes, J. E. (1975). Lung Function, 3rd edition, p. 131 . Oxford, Blackwells Scientific Publications.

DuBois, A. B. (1964). Resistance to breathing in Handbook of Physiology, section 3, volume I, $x$ chapter 16. Edited by W. O. Fenn and H. Rahn. American Physiological Society, Washington.

DuBois, A. B., Botelho, S. Y., Bedell, G. N. Marshall, R., and Comroe, J. H. (1956a). A rapid plethysmographic method for measuring thoracic gas volume:0 A comparison with a nitrogen washout method for measuring functional residual capacity in normat subjects. Journal of Clinical Investigation, 35, 322-

326.
DuBois, A. B., Botelho, S. Y., and Comroe, J. Ho (1956b). A new method for measuring airway resistance in man using a body plethysmograph: values in normal subjects and in patients withorespiratory disease. Journal of Clinical Investigation 35, 327-335.

Gayrard, P., Orehek, J., Grimaud, C., and Charpin, J® (1975). Bronchoconstrictor effects of a deep inspiration in patients with asthma. American Review of Respiratory Disease, 111, 433-439.

Hruby, J. and Butler, J. (1975). Variability of routine pulmonary function tests, Thorax, 30, 548-553.

Kerr, H. D. (1973). Diurnal variation of respiratoryo function independant of air quality. Archives of Environmental Health, 26, 144-152. 
Lloyd, T. C., and Wright, G. W. (1963). Evaluation of methods used in detecting changes of airway resistance in man. American Review of Respiratory Disease, 87, 529-537.

Lord, P. W., and Brooks, A. G. F. (1977). A comparison of manual and automated methods of measuring airway resistance and thoracic gas volume. Thorax, 32, 60-66.

Sackner, M. A., and Landa, J. (1973). Bullous disease of the lung: with relatively unimpaired ventilatory function and minimal or absent hyperinflation. Bulletin de Physio-Pathologie Respiratoire, 9, 945960.

Spicer, W. S., Storey, P. B., Morgan, W. K. C., Kerr, H. D., and Standiford, N. E. (1962). Variation in respiratory function in selected patients and its relation to air pollution. American Review of Respiratory Disease, 86, 705-712.

Stamm, A. M., Clausen, J. L., and Tisi, G. M. (1976). Effects of aerosolized isoproterenol on resting myogenic tone in normals. Journal of Applied Physiology, 40, 525-532.

Requests for reprints to: Dr. P. W. Lord, MRC Toxicology Unit, Clinical Section, St. Bartholomew's Hospital Medical College, Charterhouse Square, London EC1M 6BQ. 